\title{
A Neutron Tomographic Analysis of Plated Silver Coins from Ancient Greece Official or Illegal?
}

\author{
Scott Olsen' a1 *, Filomena Silvemini ${ }^{\text {b1 }}$, Vladimir Luzin ${ }^{\mathrm{c} 1,3}$, Ulf Garbe ${ }^{\mathrm{d} 1}$, \\ Max Avdeev ${ }^{\mathrm{e} 1}$, Joel Davis ${ }^{\mathrm{f1}}$ and Ken Sheedy ${ }^{\mathrm{g} 2}$ \\ ${ }^{1}$ ANSTO New Illawarra Rd Lucas Heights, NSW 2234, Australia \\ ${ }^{2}$ Macquarie University, Macquarie NSW 2109 Australia \\ ${ }^{3}$ The University of Newcastle, Callaghan, New South Wales 2308, Australia

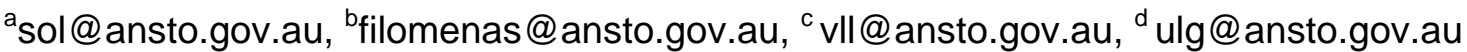 \\ 'max@ansto.gov.au. ${ }^{\mathrm{f}} \mathrm{jda} @ a n s t o . g o v . a u{ }^{\mathrm{g}}$ ken.sheedy@mq.edu.gov.au
}

\section{Keywords: Neutron Tomography, Numismatics, Archaeometallugy}

\begin{abstract}
This study focuses on a neutron tomographic analysis conducted on a set of plated silver coins minted in the city-state of Athens and in the Greek colonies of Kroton and Metapontum (South Italy or Magna Graecia) during the $6^{\text {th }}$ and $5^{\text {th }}$ centuries BC. The investigation aims to define the plating method by characterising the morphological and structural features of the specimens, i.e. the volume fraction of metallic and non-metallic components, and thickness maps of the plating and porosity. The status of these coins is uncertain: were they official issues authorized by state-authorities during periods of trouble (and silver shortages in the public treasury) or the product of ancient or modern counterfeiters?
\end{abstract}

\section{Introduction}

In the 6th century $\mathrm{BC}$ different techniques of coin manufacture were employed by mints in mainland Greece and in the Greek colonies in Southern Italy. In Greece these techniques were evidently derived from the Lydians and consisted in striking a piece of cast metal of predetermined weight (a 'blank' or flan) between two engraved dies made of hardened bronze [1] [2]. Colonies in Magna Graecia, however, uniquely developed another set of minting techniques to produce what today is called incuse coinage [3]. One of the most distinctive feature of these incuse issues lies in the fact that the reverse type is the same as that on the obverse but is rendered as a 'negative' or 'incuse' image sunk into the flan. The study of this technique is part of a dedicated on-going project [4] [5] [6]. It is evident that plated coins begin to appear at the very earliest stage in the history of coinage, and then become common place under the Romans [7] [8] [9] [10]. Plating, of course, involved an important modification of the mint's usual production processes - as has been explored by La Niece [11]. Were these plated coins issued by ancient state-authorities or the product of illegal counterfeiters? In an attempt to gain a better understanding of the technology of plated coins, numismatic and historical studies were combined together with metallurgical research based on neutron methods.

\section{Materials and Methods}

The numismatic collection of the Australian Centre for Ancient Numismatic Studies (ACANS) at Macquarie University in Sydney (AU) includes silver coins minted in cities of the Greek mainland and Magna Graecia. It includes three specimens, one each from Athens, Metapontum and Kroton that are plated. On the coin from Metapontum (inv. 07GS527), mineralisation is visible on the silver surface as green-blue deposits. These deposits are typically associated with the corrosion of copper; their presence could be explained either as contamination from the 
burial contest or as a sign of plating. The coin from Kroton (inv. 16A25) showed the presence of a multilayered coating on the protruding ridge. Finally, the coin from Athens (inv. 14A09), one of the first issues of coinage struck by that city, had been cut in half perhaps once it had been discovered to be plated; the cut clearly shows the copper core concealed underneath the silver plating (Table 1).

In order to properly describe the plated coin, and to clarify the manufacturing technique, the morphology and bulk structure of each was investigated by means of neutron tomography. This method is a valuable analytical tool to extract and quantify information such as morphology, porosity inclusions and the presence of composite structures. Most importantly neutron tomography is non-destructive. As demonstrated in [4], by detecting and evaluating structural features, relevant information on the manufacturing process can be inferred.

Table 1: Inventory number, provenance and physical details are listed for the three coins. [5] [6]

\begin{tabular}{|c|c|c|c|}
\hline Inv. & 07GS527 & $16 \mathrm{~A} 25$ & $14 \mathrm{~A} 09$ \\
\hline & & & \\
& & & \\
& & & \\
& & & \\
\hline City & Metapontum & Kroton & Athens \\
\hline Year & $510-470 \mathrm{BC}$ & $510-480 \mathrm{BC}$ & $525-515 \mathrm{BC}$ \\
\hline Diameter & $24 \mathrm{~mm}$ & $\sim 20 \mathrm{~mm}$ & $\sim 17 \mathrm{~mm}$ \\
\hline Weight & $8.1 \mathrm{~g}$ & $7.4 \mathrm{~g}$ & $6.7 \mathrm{~g}$ \\
\hline
\end{tabular}

The neutron tomography analysis was performed on DINGO, the ACNS ${ }^{1}$ neutron imaging instrument located on a thermal beam tangentially facing the 20MW OPAL research reactor at ANSTO $^{2}$, Sydney [12].

The measurements were conducted in the high-resolution acquisition mode (with the ratio of collimator-detector length $L$ to inlet collimator diameter $D$ equals to 1000) with a pixel size of 27 $\mu \mathrm{m}$ by setting a $55 \times 55 \mathrm{~mm}^{2}$ field of view with $100 \mathrm{~mm}$ lens coupled with a $50 \mu \mathrm{m}$ thick scintillation screen. In this configuration, up to 4 samples can be mounted in an aluminium cylindrical holder and measured at the same time. The coins were spaced with aluminium foil. Projections were acquired with an equiangular step of $0.25^{\circ}$ over $360^{\circ}$ with an exposure time of 50 seconds each, resulting in a total scan time of about 20 hours. The data set were reconstructed with Octopus package [13], while AVIZO [14] was used for visualization and analyses.

\section{Results and discussion}

Results from the tomographic analysis confirmed that all selected specimens are plated (Figure 1). The virtual cross sections through the tomographic reconstructions show a homogeneous copper core in all coins. A silver layer surrounds the core with porosities localised at their interface (Figure 2). The amount and size of pores were quantified (Table 2). Analysis also showed variation in the thickness and distribution of the silver coating (Figure 3) as well as the copper and silver volume fractions in the samples (Table 3). This analysis is part of a broader program of investigation that includes neutron diffraction, neutron texture analysis, and SEMEDS analyses. The study is still in progress; here we present a selection of interesting results

\footnotetext{
${ }^{1}$ Australian Centre for Neutron Scattering

${ }^{2}$ Australian Nuclear Science and Technology Organisation
} 
based on neutron tomographic analysis and refer the reader to other publications for more a detailed coverage of earlier research [5] [6].

Sample 07GS527 (Metapontum). The neutron tomographic reconstruction clearly shows a fine layer of silver wrapped around a copper base. The coating is evenly distributed with an average thickness of $0.28 \mathrm{~mm}$ and constitutes $32.9 \%$ of the coin volume. The structure of the lamina suggests that a silver foil was bonded to the copper core by a diffusion (metallurgical) bonding process. During the process the core was wrapped in pure silver foil and rapidly heated until it was close to the melting point of silver for a short time. Good control of temperature was required to prevent the core melting and the copper from being too rapidly diffused into the silver. Complementary investigation on the High Resolution Powder Diffractometer ECHIDNA [15] at ANSTO confirmed the presence of copper and silver by obtaining full diffraction patterns. No evidence of any other metal constituents, including low temperature melts that could have acted as soft soldering materials, were identified in the diffraction pattern [5]. A low amount $(0.1 \mathrm{vol} . \%)$ of small porosities (average volume of $0.01 \mathrm{~mm}^{3}$ ) are localised at the rim of the coin; this suggests that they were probably created during the plating process through the imperfect adhesion of the silver foil to the core on the coin periphery.

Sample 16A25 (Kroton). The peculiar feature detected in this coin is a multilayered coating constituted by three layers of silver over the copper core. The overall plating, quantified to be around 36.8 vol. \%, has a variable thickness, ranging from a minimum of 0.06 to a maximum $3.75 \mathrm{~mm}$ in the protruding ridge, with an average value of $0.46 \mathrm{~mm}$. The gaps detected between the silver foils resulted in a larger amount of pores ( $0.8 \mathrm{vol}$. \%) and on average bigger porosities (volume of $0.2 \mathrm{~mm}^{3}$ ) in comparison to the sample from Metapontum (07GS527). It is probable that the coin was recoated as a result of a manufacturing defect. Since no trace of solder was identified, it is assumed that, again the diffusion bonding technique was adopted.
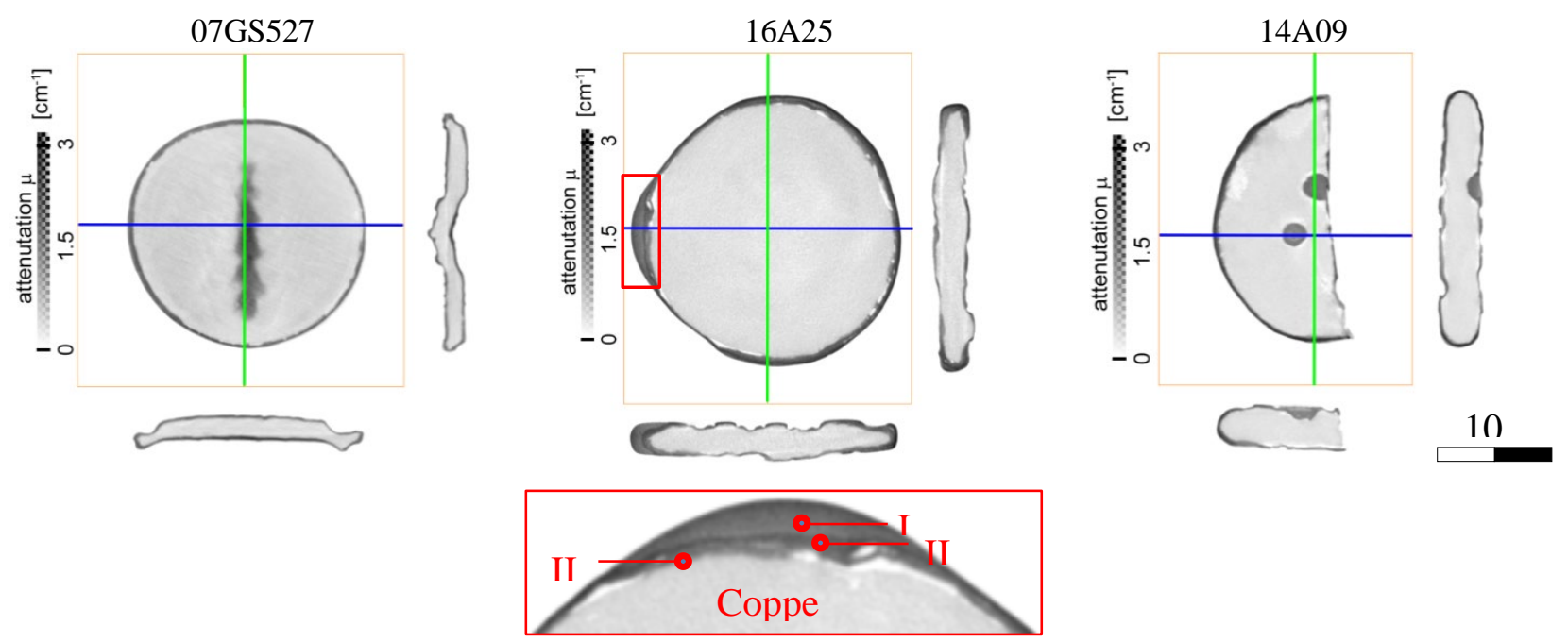

Figure 1: Maps of the planes cropping the reconstructed volume of each coin are shown together with the corresponding cross sections. The scale bar at the left of each figure indicates the colour code for the attenuation coefficient. A detailed view of the multi-layered plating is reported for coin $16 A 25$ at the bottom.

Sample 14A09 (Athens). Some observations can be drawn about the plating of the Athenian coin based on the tomographic reconstruction. The average thickness of the foil is similar to the sample from Metapontum $(0.34 \mathrm{~mm})$ but less evenly distributed; it constitutes $19 \mathrm{vol}$. \% of the total volume, a very small amount in comparison to the previous samples. Most of the coin is 
made of a homogenous copper core that appears heavily corroded at the interface with the plating, and on the exposed cut surface. At the interface between silver coating and copper core, pores are visible. These can be also attributed to the diffusion of corrosion products. The level of porosity is the highest among the three coins discussed in this paper (1.7 vol. \%). On average the size of the pores is similar to those in coin 16A25 (Kroton) but with a higher variability (up to a volume of $1.92 \mathrm{~mm}^{3}$ ). Two undefined inserts are visible in 14A09. These two elements, featuring a drop-like shape, were identified as indentation from the plating into the core. They might be interpreted as plugs applied to repair two holes in the original plating, holes that would reveal the copper core and shown the possessor that it was not of the expected metal value (Figure 2).
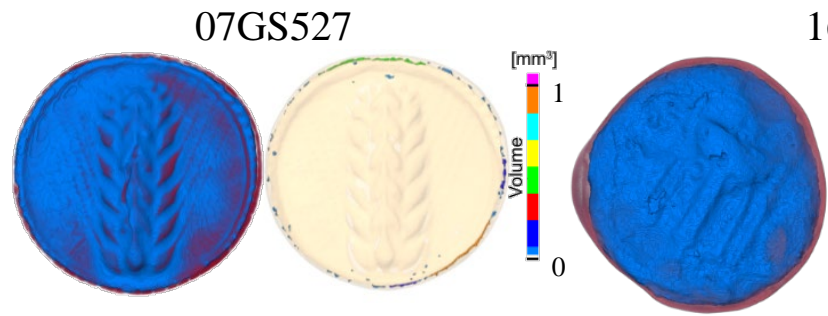

16A25
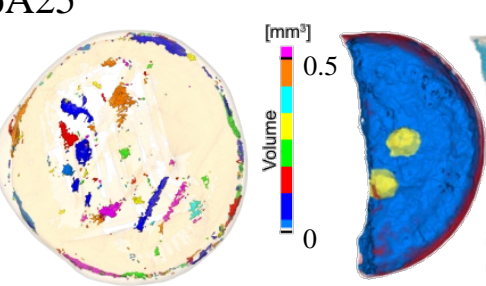

14A09

plating $\square$ core $\square$ corrosion $\square$ plug

Figure 2: Left, the structural components are separated and rendered in different colour for each sample; the colour code is expressed by the legend on the bottom. Right, the maps show the distribution of porosities. A scale bar on the right side of each figure indicates the coding colour-volume.

07GS527

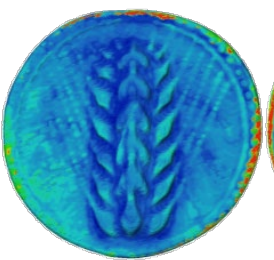

Thickness [mm]

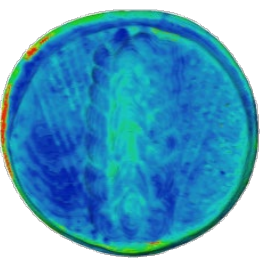

0 1
16A25

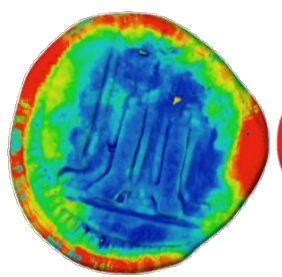

Thickness $[\mathrm{mm}]$
14A09

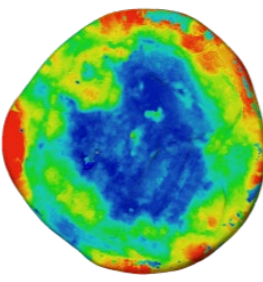

0
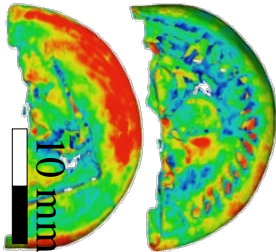

Thickness $[\mathrm{mm}]$

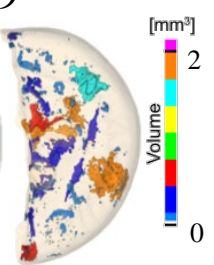

$10 \mathrm{~mm}$

Figure 3: The thickness of the silver plating is reported in false colour for the obverse and revere of each coin. A scale bar indicates the coding colour-thickness.

All 3 coins were fabricated using the diffusion bonding technique, but neutron tomography has revealed noticeable variations in the quality of the coins in terms of the silver to copper ratio and porosity.

Table 2: Statistical analysis of porosities

\begin{tabular}{|c|c|c|c|c|c|c|c|c|c|c|}
\hline & \multirow[t]{2}{*}{ Feret shape } & \multicolumn{3}{|c|}{ Equivalent diameter [mm] } & \multirow{2}{*}{$\frac{\text { Ave. width }}{\text { [mm] }}$} & \multirow{2}{*}{$\frac{\text { Ave. length }}{[\mathrm{mm}]}$} & \multirow[t]{2}{*}{ Aspect ratio } & \multicolumn{3}{|c|}{ Volume [mm3] } \\
\hline & & $\min$ & $\max$ & average & & & & $\min$ & $\max$ & average \\
\hline 07GS527 & 2.79 & 0.10 & 0.55 & 0.19 & 0.21 & 0.75 & 0.28 & 0.00 & 0.09 & 0.01 \\
\hline 16A25 & 2.26 & 0.10 & 1.05 & 0.23 & 0.21 & 0.60 & 0.35 & 0.00 & 0.61 & 0.02 \\
\hline 14A09 & 1.80 & 0.03 & 1.54 & 0.12 & 0.14 & 0.31 & 0.46 & 0.00 & 1.92 & 0.02 \\
\hline
\end{tabular}


Table 3: Results of the plating and porosity analysis of the 3 silver plated coins.

\begin{tabular}{|c|c|c|c|c|c|}
\hline & & & 07GS527 & 16A25 & 14A09 \\
\hline \multirow{3}{*}{ Plating feature } & Min/max thickness & \multirow{2}{*}{$\mathrm{mm}$} & $0.13-1.49$ & $0.06-3.75$ & $0.06-0.80$ \\
\hline & Mean & & 0.28 & 0.46 & 0.34 \\
\hline & Standard Deviation & & 0.11 & 0.36 & 0.19 \\
\hline \multirow{5}{*}{ Volume } & Total & $\mathrm{cm}^{-3}$ & 0.42 & 0.83 & 0.73 \\
\hline & Porosity & \multirow{4}{*}{$\%$} & 0.1 & 0.8 & 1.7 \\
\hline & Silver & & 32.9 & 36.8 & 19 \\
\hline & Copper & & 67 & 62.4 & 70.5 \\
\hline & Plugs \& Mineralisation & & - & - & 8.8 \\
\hline \multirow{2}{*}{ Mass } & Silver & \multirow[b]{2}{*}{ g } & 1.5 & 3.2 & 1.5 \\
\hline & Copper & & 6.6 & 4.2 & 5.2 \\
\hline
\end{tabular}

The Metapontum coin 07GS527 is a technically accomplished product with a very uniform silver layer, minor porosity and a silver-copper ratio of 0.2 (Table 3). The coin from Kroton 16A25 was replated and its silver-copper ratio is the highest (0.4) among the investigated samples. This was due to the additional plating on the ridge as shown in figure 3 . On this basis the coin might be an authentic specimen recoated by the official mint of Kroton, it is very unlikely to be a modern forgery as the plating is clear. Further investigation by means of neutron diffraction methods, already in progress, might provide further clues. The last coin, that from Athens (14A09), which was minted according the methods typical of the Greek mainland (and not by the incuse coin processes), has a ratio of silver over copper of 0.3 . Once again there is the suggestion that the makers touched up the coin as evidenced by the two plugs seen in figure 2 . Is it possible then that recoating was a regular part of the official plating process or is this evidence of an illegal counterfeit?

Successful plating (which completely concealed the underlying base metal core) required a high degree of technical skill, and in the examples we have studied we appear to have evidence that first attempts were not always convincing. Should we conclude that a low level of expertise is indicative of a forger? Can we assume that an official mint could be expected to have artisans competent in plating and therefore if the job was 'botched' it is likely that we are looking at a counterfeit coin? Plated coins, however, were never a regular part of the job of an official mint and until recently it was widely believed that official mints did not produce plated or counterfeit coins [16]. Indeed there is still a general view among numismatists and ancient historians that all plated coins inevitably are fakes [16]. The critical question is 'who is producing the plated coins'? La Niece has made the claim that official mints used manufacturing techniques suitable for mass production of coins but the forger could afford to use relatively labour-intensive methods [11]. But is this juxtaposition true? Ancient city-states only resorted to plating coins when they were in difficulties. Herodotus (Book 3.56) tells a story, for example, that the Samians coated lead with electrum to produce coins to bribe the Spartans to raise the siege of the Samos. It then seems possible in such circumstances where the survival of the city depended on acceptance of the plated coin that special effort would have gone into making sure that this money was believable.

\section{Conclusion}

In exploring the plating technique of a set of coins from the ACANS collection at Macquarie University in Sydney (AU), neutron tomography provided critical information on macrostructure and morphology. In all cases the silver plating was applied by diffusion bounding to a copper core, but noticeable differences in the coating structure, and in the silver-copper ratio suggest different procedures, variations in effort required to complete the work, and finally variation in the expertise available to undertake plating. 
Our studies of these coins, which in two cases show evidence of recoating, rather than pointing to unofficial counterfeiting, in fact point to the amount of effort that was always needed to make sure the plated coins were acceptable. Ancient states would not have issued plated coins on a regular basis. They were a last resort in times of crisis. It is quite possible that these mints did not have workers trained to produce competent plated coins.

\section{References}

[1] D. Sellwood, "Some experiments in Greek minting technique,” NC, vol. 7, no. 3, p. 217231, 1963.

[2] D. M. Schaps, "The Invention of Coinage and the Monetization of Ancient Greece," 2004. https://doi.org/10.3998/mpub.17760

[3] N. Rutter, Historia Numorum. Italy., London, 2001.

[4] F. Salvemini, S. R. Olsen, V. Luzin, U. Garbe, J. Davis, T. Knowles and K. Sheedy, "Neutron tomographic analysis: Material characterization of silver and electrum coins from the 6th and 5th centuries BCE.," Materials Characterization , vol. 118, pp. 175-185, 2016. https://doi.org/10.1016/j.matchar.2016.05.018

[5] F. Salvemini, K. Sheedy, S. R. Olsen, M. Avdeev, J. Davis and V. Luzin, "A multitechnique investigation of the incuse coinage of Magna Graecia," Journal of Archaeological Science: Report, pp. 748-755, 2018. https://doi.org/10.1016/j.jasrep.2018.06.025

[6] K. A. Sheedy, P. Munroe, F. Salvemini and V. Luzin, "An incuse stater from the series 'Sirinos/Pyxoes',” Journal of the Numismatic Association of Australia, vol. 26, pp. 36-52, 2015.

[7] R. Wallace, "The Production and Exchange of Early Anatolian Electrum Coinages," Revue des Etudes Anciennes , pp. 87-94, 1989. https://doi.org/10.3406/rea.1989.4367

[8] G. M. Ingo, S. Balbi, T. de Caro, I. Fragala and C. Riccucci, "Microchemical investigation of Greek and Roman silver and gold plated coins: coating techniques and corrosion mechanisms," Applied Physics A, vol. 84, no. 4, pp. 623-629, 2006. https://doi.org/10.1007/s00339-006-3536-x

[9] A. Deraisme, L. Beck, F. Pilon and J. Barrando, "A study of the silvering process of the Gallo-Roman coins forged during the third century ad.," Archaeometry, vol. 48, no. 3, pp. 469480, 2006. https://doi.org/10.1111/j.1475-4754.2006.00267.x

[10] K. Anheuser and . P. Northover , "Silver Plating on Roman and Celtic Coins from Britain - a Technical Study,” British Numismatic Journa, vol. 64, pp. 22-32.

[11] S. La Niece, "Technology of Silver-Plated Coin Forgeries," Metallurgy in Numismatics, vol. 3, pp. 227-239, 1993.

[12] U. Garbe, T. Randall, C. Davidson, G. Pangelis and S. Kennedy, “A New Neutron Radiography / Tomography / Imaging Station DINGO at OPAL,” Physics Procedia, vol. 69, pp. 27-32, 2015. https://doi.org/10.1016/j.phpro.2015.07.003

[13] M. Dierick, B. Masschaele and L. Van Hoorebeke, "Octopus, a fast and user-friendly tomographic reconstruction package developed in LabView ${ }^{\circledR}$,” Measurement Science and Technology, vol. 15, no. 7, 2004. https://doi.org/10.1088/0957-0233/15/7/020

[14] “FEI,” [Online]. Available: https://www.fei.com/software/amira-avizo/] .

[15] K.-D. Liss, B. Hunter, M. Hagen, T. Noakes and S. Kennedy, "Echidna-the new highresolution powder diffractometer being built at OPAL,” Physica B: Condensed Matter, vol. 385386, no. 2, pp. 1010-1012, 2006. https://doi.org/10.1016/j.physb.2006.05.322

[16] P. Van Alfen, "Problems in ancient imitative and counterfeit coinage," in Making, moving and managing : the new world of ancient economies, 323-31 BC, Z. Archibald and el al., Eds., p. 354. 